\title{
Effect of Using Waste Material as Filler in Bituminous Mix Design
}

\author{
Dipu Sutradhar ${ }^{*}$, Mintu Miah, Golam Jilany Chowdhury, Mohd. Abdus Sobhan
}

Department of Civil Engineering, Rajshahi University of Engineering \& Technology, Rajshahi, Bangladesh

\section{Email address:}

dipu.ruet.civil@gmail.com (D. Sutradhar),mintu@ruet.ac.bd (M. Miah), zilanichoudhuri@gmail.com (G. J. Chowdhury), msobhan@yahoo.com (Mohd. A. Sobhan)

\section{To cite this article:}

Dipu Sutradhar, Mintu Miah, Golam Jilany Chowdhury, Mohd. Abdus Sobhan. Effect of Using Waste Material as Filler in Bituminous Mix Design. American Journal of Civil Engineering. Vol. 3, No. 3, 2015, pp. 88-94. doi: 10.11648/j.ajce.20150303.16

\begin{abstract}
Bituminous concrete or asphaltic concrete is one of the highest and costliest types of flexible pavement layers used in surface course. Being of high cost specifications, the bituminous mixes are properly designed to satisfy the design requirements of the stability and durability. The mixture contains dense grading of coarse aggregate, fine aggregate and mineral filler coated with bitumen binder. The mineral filler passing through $0.075 \mathrm{~mm}$ sieve performs some important roles in bituminous mixes. Marshall Stability of bituminous mix increases as the amount of filler increases. The Asphalt Institute recommends the use of 4 to $8 \%$ filler in asphalt concrete. The common filler materials like cement, lime stone, granite powder etc. is not easily and economically available in Bangladesh. Waste concrete dust and brick dust are considered to be cheaper and in abundant supply in Bangladesh. In this study an attempt is made to find the effect of types of filler on the behavior of bituminous mixes. According the properties of bituminous mixes containing filler like waste concrete dust and brick dust is studied and compared with the mixes containing filler like fine sand and stone dust mixture generally used. The Marshall method of mix design was used for the comparison. The Marshall stabilities of mix types containing filler fine sand and stone dust mixture, waste concrete dust and brick dust were found $9.8 \mathrm{KN}, 11.1 \mathrm{KN}$ and $11.3 \mathrm{KN}$ respectively which satisfy the limiting value of 5.33 $\mathrm{KN}$ according to Marshall Design criteria. The study indicates the possibility of using waste concrete dust and brick dust as filler in bituminous mix.
\end{abstract}

Keywords: Bituminous Paving Mixes, Brick Dust, Waste Concrete Dust, Stone Dust, Filler, Marshall Mix Design

\section{Introduction}

Bituminous roads are defined as the roads in the construction of which bitumen is used as binder. It consists of an intimate mixture of aggregates, mineral filler and bitumen. The quality and durability of bituminous road is influenced by the type and amount of filler material is used. [1] The filler tends to stiffen the asphaltic cement by getting finely dispersed in it. Various materials such as cement, lime, granite powder, stone dust and fine sand are normally used as filler in bituminous mixes. Cement, lime and granite powder are expensive and used for other purposes more effectively. Fine sand, ash, waste concrete dust and brick dust finer than 0.075 $\mathrm{mm}$ sieve size appear to be suitable as filler material. The use of waste powder as filler in asphalt mixture has been the focus of several research efforts over the past few years. Phosphate waste filler [2], Jordanian oil shale fly ash [3], bag house fines [4], recycled waste lime [5], municipal solid waste incineration ash [6] and waste ceramic materials [7] have been investigated as filler. It was proved that these types of recycled filler could be used in asphalt mixture and gave improved performance. So the present study has been taken in order to investigate the behavior of bituminous mixes with different types of filler materials locally available.

If filler is mixed with less bitumen than it is required to fill its voids, a stiff dry product is obtained which is practically not workable. Overfilling with bitumen, on the contrary, imparts a fluid character to the mixture. [8]The filler has the ability to increase the resistance of particle to move within the mix matrix and/or works as an active material when it interacts with the asphalt cement to change the properties of the mastic. [9] Elastic modulus of asphalt concrete mixture can increases by the addition of mineral filler. But excessive amount of filler may weaken the mixture by increasing the amount of asphalt needed to cover the aggregates $[10,11]$.The effects of these fillers are also dependent on gradations.

The objective of this study is to produce an 
aggregate-asphalt mix with a controlled void. If the void of the mixed aggregate is too low, the mix will be unable to carry sufficient asphalt and therefore will be difficult to compact due to insufficient lubrication. It will not be sufficiently durable as the film on the aggregate particles will be too thin. On the other hand, if the void is too high, it is probable that the mix will be lacking in stability. Because each aggregate will receive less support from those surrounding it. [12, 13] Fillers could improve the temperature susceptibility and durability of the asphalt binder and asphalt-concrete mixture. The effects of these fillers are also dependent on gradations. To have a good mixture, aggregates and filler should bind properly. [14] A strong backbone for the mixture can provided by the good packing of the coarse, fine, and filler aggregates.

The performance of bituminous mix also depends on amount of filler in the mix. [15] The workability of a mix depends, to some extent, on the amount and type of the filler present in the mix. $[16,17]$ The mixture performance also affected by the interactions between asphalt and filler because of the larger surface area, filler may absorb more asphalt and its interaction with asphalt may lead to different performance of asphalt-concrete mixture. [18] The size distribution, particle shape, surface area, surface texture, voids content, mineral composition, and other physiochemical properties vary for several fillers. Therefore, their effect on the properties of asphalt-concrete mixture also varies.

Conventionally in Bangladesh, fine sand with stone dust is used as filler material in bituminous mix. In this study an attempt is made to find the effect of types of cheap \& non-conventional filler on the behavior of bituminous mixes. For this purpose, Waste concrete dust and brick dust were used as non-conventional fillers. The performance characteristics of the mixture containing different types of filler were evaluated by examining fundamental material properties and by performing various laboratory tests. Then results obtained for mix type containing non-conventional fillers were compared with the results obtained for mix type containing conventional filler. The possibility of using non conventional filler (e.g. waste concrete dust and brick dust) are also investigated.

\section{Materials}

A bituminous mixture is normally composed of aggregate and bitumen. The aggregates are generally divided into coarse, fine and filler fractions according to the size of the particles. The following sections include the description of the coarse aggregate, fine aggregate, mineral fillers and bitumen used in this study.

\subsection{Coarse Aggregate}

Coarse aggregate for bituminous mix has been defined as that portion of the mixture which is retained on $2.36 \mathrm{~mm}$ (No. 08) sieve according to the Asphalt Institute. Basalt rock was used as coarse aggregate. It was crushed manually and brought to the sizes $25.0 \mathrm{~mm}$ or less. The aggregates were then sieved using U.S. standard sieves and separated out in different fractions.

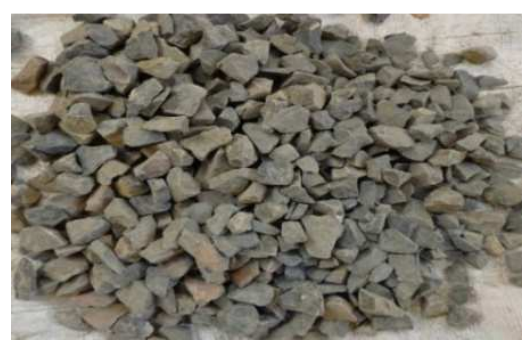

Figure 1. Appearance of coarse aggregate.

\subsection{Fine Aggregate}

Aggregate passing through $2.36 \mathrm{~mm}$ sieve and retained on $0.075 \mathrm{~mm}$ sieve was selected as fine aggregate. Domar sand was the source of fine aggregates.

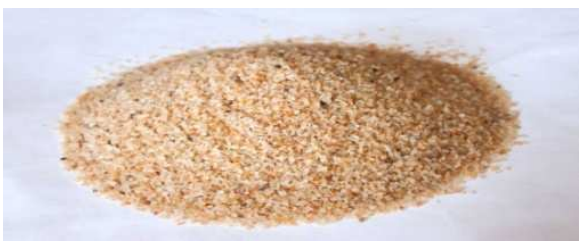

Figure 2. Appearance of fine aggregate.

\subsection{Filler}

Fine sand and stone dust mix, waste concrete dust and brick dust finer than $0.075 \mathrm{~mm}$ size sieve were used as filler in the bituminous mixes for comparison and economical point of view.

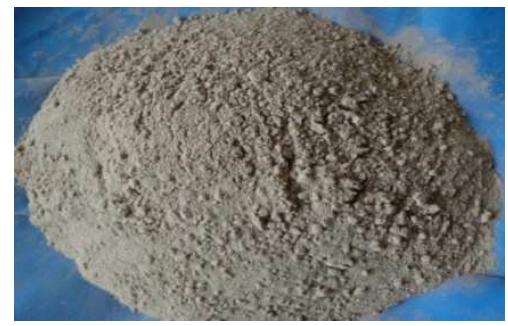

Figure 3. Appearance of fine sand and stone dust mix.

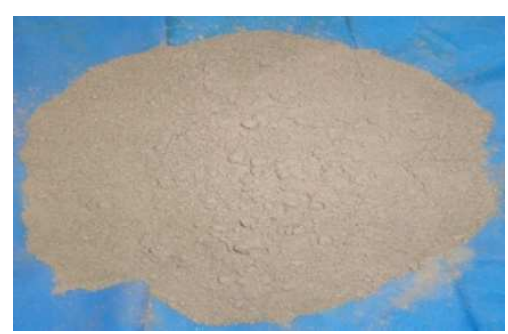

Figure 4. Appearance of waste concrete dust.

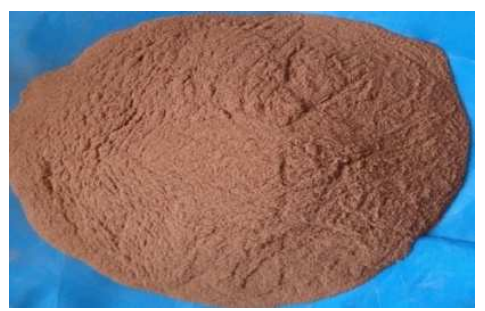

Figure 5. Appearance of brick dust. 


\subsection{Bitumen}

In this study 85-100 grade bitumen was used. Same bitumen was used for all the mixes so the type and grade of binder would be constant.

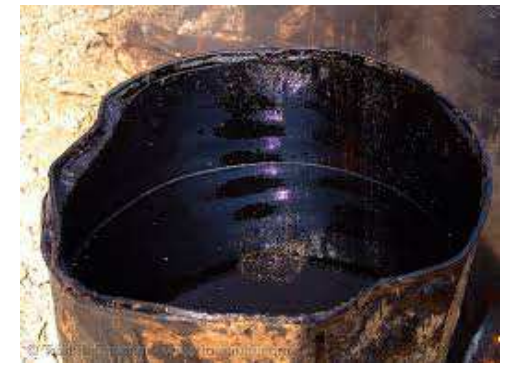

Figure 6. Appearance of bitumen.

\section{Methods}

\subsection{Laboratory Tests for the Properties of Materials}

\subsubsection{Properties of Aggregates}

Tests were performed to determine the Aggregate Crushing Value, Aggregate Impact Value, Specific gravity, L.A Abrasion value and Water absorption according to the procedures specified by AASHTO and BS standards and results are summarized in Table 1.

Table 1. Physical Properties of aggregates.

\begin{tabular}{lllll}
\hline \multirow{2}{*}{ Properties } & \multirow{2}{*}{ AASHTO/BS Designation } & \multicolumn{2}{c}{ Aggregates } & \multirow{2}{*}{ Standard values (AASHTO) } \\
\cline { 3 - 4 } & & Coarse & Fine & $<30 \%$ \\
\hline Aggregate Crushing Value (\%) & BS812:Part3 & 12 & - & $<30 \%$ \\
Aggregate Impact Value (\%) & BS812:Part3 & 20 & - & $2.60-2.90$ \\
Specific gravity & T85 & 2.84 & 2.89 & $<40$ \\
L.A Abrasion value(Grade A) & T96 & 15 & - & \\
\hline
\end{tabular}

\subsubsection{Properties of Filler}

Tests were performed to determine the specific gravity of filler fine sand with stone dust, waste concrete dust and brick dust according to the procedures specified by AASHTO and given in Table 2 .

Table 2. Physical Properties of fillers.

\begin{tabular}{lll}
\hline Filler type & $\begin{array}{l}\text { AASHTO } \\
\text { Designation }\end{array}$ & Specific gravity \\
\hline Fine sand and stone dust mix & T85 & 2.71 \\
Waste concrete dust & T85 & 2.43 \\
Brick dust & T85 & 2.34 \\
\hline
\end{tabular}

\subsubsection{Properties of Bitumen}

Penetration, specific gravity, ductility, softening point, flash and fire point of bitumen were determined according to the procedure specified by AASHTO standards. Properties of bitumen used in bituminous mix are given in Table 3

Table 3. Properties of bitumen.

\begin{tabular}{llll}
\hline Properties & $\begin{array}{l}\text { AASHTO } \\
\text { Designation }\end{array}$ & $\begin{array}{l}\text { Test } \\
\text { Value }\end{array}$ & $\begin{array}{l}\text { Standard } \\
\text { Values(AASHTO) }\end{array}$ \\
\hline $\begin{array}{l}\text { Penetration }(1 / 10 \\
\text { mm })\end{array}$ & th & 96 & $85-100$ \\
$\begin{array}{l}\text { Specific Gravity } \\
\text { Ductility(mm) }\end{array}$ & $\mathrm{T} 229$ & 1.03 & $1.01-1.05$ \\
Softening Point $\left({ }^{\circ} \mathrm{C}\right)$ & $\mathrm{T} 51$ & $100^{+}$ & $\mathrm{Min} .100$ \\
Flash Point $\left({ }^{\circ} \mathrm{C}\right)$ & $\mathrm{T} 48$ & 48 & $45^{\circ} \mathrm{C}-52^{\circ} \mathrm{C}$ \\
Fire Point $\left({ }^{\circ} \mathrm{C}\right)$ & $\mathrm{T} 48$ & 295 & $280^{\circ} \mathrm{C}-300^{\circ} \mathrm{C}$ \\
\hline
\end{tabular}

\subsection{Marshall Mix Design}

In this research work Marshall Stability testing setups was used. Tests were performed to determine the Marshall stability, flow value, optimum bitumen content and amount of bitumen required for mix types containing different filler. To investigate the Marshall stability of bituminous mixes with different fillers 45 specimens of $101.6 \mathrm{~mm}$ diameter and approximately $63.5 \mathrm{~mm}$ thickness were prepared. It was observed from preliminary trails that about 1200 grams of aggregates were required to prepare one specimen of 101.6 $\mathrm{mm}$ (4 inch) diameter and $63.5 \mathrm{~mm}$ (2.5 inch) thick. Three specimens were prepared for each bitumen contents and 5 bitumen contents ( $4 \%$ to $6 \%$ ) were used with an increment of $0.5 \%$ by weight of total mix. Preparation of specimen, compaction and testing were performed according ASTM D1559 (Marshall Mix Design Method). The aggregates and bitumen were rapidly mixed to yield a mixture having a uniform distribution of bitumen throughout. The bulk specific gravity and density, theoretical maximum specific gravity was determined according to ASTM D2726, ASTM D2041 respectively. After determination of specific gravities of the compacted specimens were immersed in the thermostatically controlled water bath maintained at a temperature of $60^{\circ} \mathrm{C}$ for 30 minutes. Marshall Stability and flow test were performed afterwards for each specimen by testing machine. Marshall testing machine is an electrically powered compression testing device. Load was applied to the test specimens through cylindrical segment testing heads at a constant rate of vertical strain of $51 \mathrm{~mm}$ (2inch) per minute until the maximum load was reached. The maximum load resistance and respective 
flow value were recorded and percent air voids were determined according to ASTM D3203.

\section{Results and Discussions}

Marshall Test results of compacted mix types containing filler fine sand with stone dust, waste concrete dust and brick dust are tabulated in table 4, 5 and 6 respectively. The tables contains the value of bitumen content, unit weight, Marshall Stability, flow value, percent air voids $\left(\% \mathrm{~V}_{\mathrm{a}}\right)$, percent voids in mineral aggregate (\%VMA) and percent voids filled with bitumen (\%VFB). The relationship between unit weight, Marshall Stability, flow value, percent voids in total mix $\left(\% \mathrm{~V}_{\mathrm{a}}\right)$, percent voids in mineral aggregates (\%VMA) and percent voids filled with bitumen (\%VFB) with percentage of bitumen content are shown in figure 7 to figure 12 .

Table 4. Marshall Properties of specimens with filler fine sand and stone dust mix.

\begin{tabular}{|c|c|c|c|c|c|c|}
\hline$\% \mathrm{BC}$ & Unit weight $\left(\mathrm{kg} / \mathrm{m}^{3}\right)$ & Stability(kN) & Flow value(mm) & $\mathrm{Va}(\%)$ & VMA(\%) & VFB(\%) \\
\hline 4.0 & 2348 & 8.0 & 2.50 & 6.80 & 20.1 & 66.17 \\
\hline 4.5 & 2375 & 8.8 & 2.65 & 5.10 & 19.3 & 73.58 \\
\hline 5.0 & 2391 & 9.5 & 2.83 & 3.90 & 18.8 & 79.26 \\
\hline 6.0 & 2390 & 9.3 & 3.25 & 2.50 & 19.8 & 87.37 \\
\hline
\end{tabular}

Table 5. Marshall Properties of specimens with filler waste concrete dust.

\begin{tabular}{|c|c|c|c|c|c|c|}
\hline$\%$ BC & Unit weight $\left(\mathrm{kg} / \mathrm{m}^{3}\right)$ & Stability(kN) & Flow value(mm) & $\operatorname{Va}(\%)$ & VMA(\%) & $\operatorname{VFB}(\%)$ \\
\hline 4.0 & 2358 & 9.3 & 2.57 & 7.09 & 17.8 & 60.17 \\
\hline 4.5 & 2380 & 10.1 & 2.75 & 5.30 & 16.5 & 67.88 \\
\hline 5.0 & 2395 & 10.8 & 2.93 & 4.00 & 16.2 & 75.31 \\
\hline 5.5 & 2398 & 11.1 & 3.13 & 3.10 & 16.5 & 81.21 \\
\hline 6.0 & 2393 & 10.7 & 3.38 & 2.70 & 17.5 & 84.57 \\
\hline
\end{tabular}

Table 6. Marshall Properties of specimens with filler brick dust.

\begin{tabular}{lllllll}
\hline \% BC & Unit weight $\left(\mathbf{k g} / \mathbf{m}^{\mathbf{3}}\right)$ & Stability(kN) & Flow value(mm) & Va(\%) & VMA(\%) & VFB(\%) \\
\hline 4.0 & 2341 & 9.5 & 2.67 & 7.28 & 21.5 & 66.14 \\
4.5 & 2367 & 10.3 & 2.85 & 5.5 & 20.41 & 73.05 \\
5.0 & 2385 & 11 & 3.03 & 4.2 & 20 & 79 \\
5.5 & 11.3 & 3.23 & 3.2 & 20.5 & 84.39 \\
6.0 & 2390 & 11.1 & 3.50 & 2.8 & 20.8 & 86.54 \\
\hline
\end{tabular}

Key: $\mathrm{BC}=$ Bitumen content.

For fine sand with stone dust, waste concrete dust and brick dust filler samples, the bitumen content at maximum unit weight and stability were determined from figures $7 \& 8$ respectively and bitumen content at $4 \%$ air voids in the total mix were determined from figure 10 . The average of these three bitumen content is taken as optimum bitumen content.

The amount of bitumen to be added in a mixture cannot be too much or too little. An optimum amount of bitumen should use so that the aggregate are fully coated with bitumen and the voids within the bituminous material are sealed up. As such, the durability of the pavement can be enhanced by the impermeability achieved. Moreover, a minimum amount of binder is essential to prevent the aggregates from being pulled out by the abrasive actions of moving vehicles on the carriageway.

The optimum bitumen content for waste concrete dust and brick dust were found $5.33 \%$ and $5.37 \%$ which are almost the same as the optimum value obtain for conventional filler (e.g. fine sand with stone dust). It means the filler waste concrete dust and brick dust will provide the same surface area to absorb bitumen as filler fine sand with stone dust. The Marshall properties obtained for these three types of fillers reveal that due to having slightly higher bitumen content, nonconventional filler specimens are found to exhibit higher stability value $(11 \mathrm{kN} \& 11.18 \mathrm{kN})$ compared to conventional filler specimens $(9.68 \mathrm{kN})$.

Figure 7 showing the relationship between unit weight and bitumen content indicates that the unit weight of compacted specimens for the mix increases initially with an increase in bitumen content, reaches a maximum value and then decreases. This is because while bitumen content increases in the mix, it fills the voids hence increase unit weight.

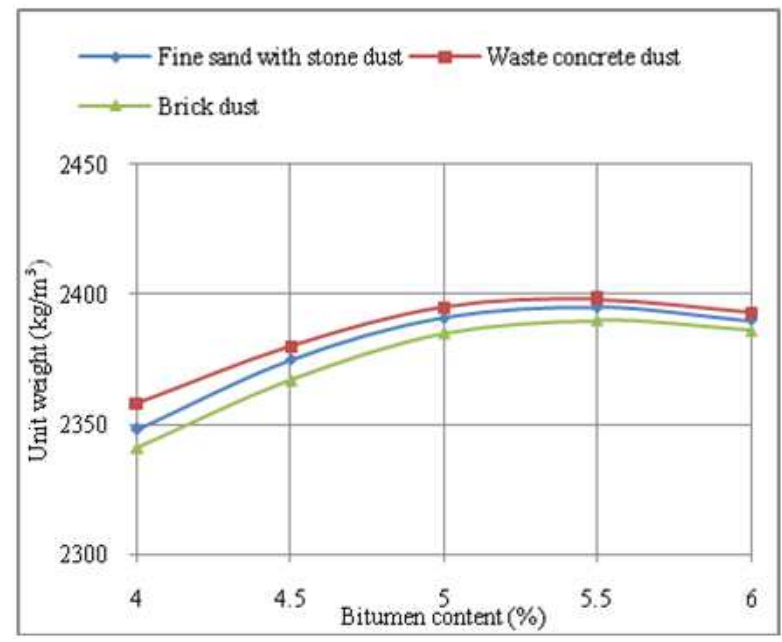

Figure 7. Variation of unit weight with bitumen content (\%). 


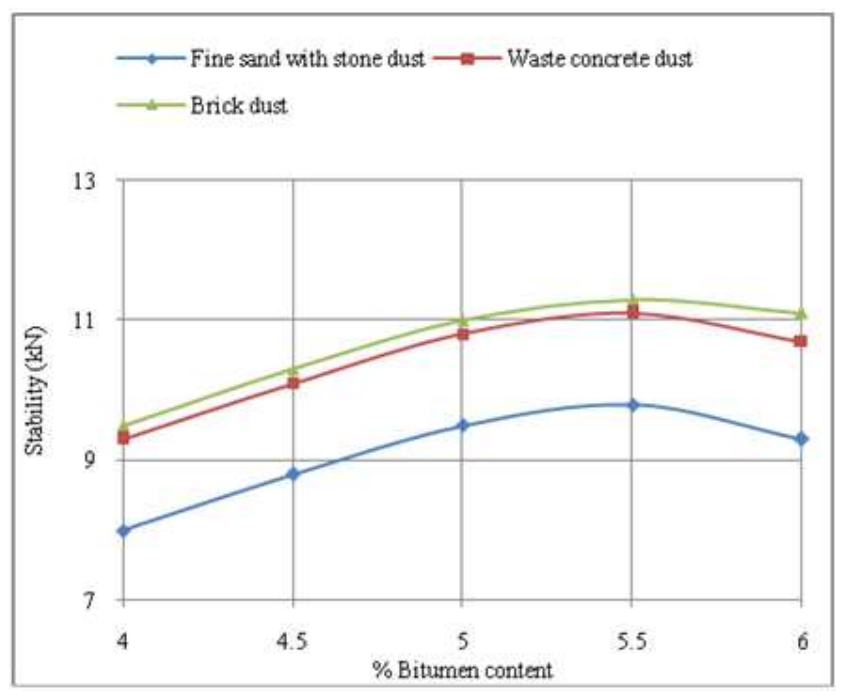

Figure 8. Variation of stability with bitumen content (\%).

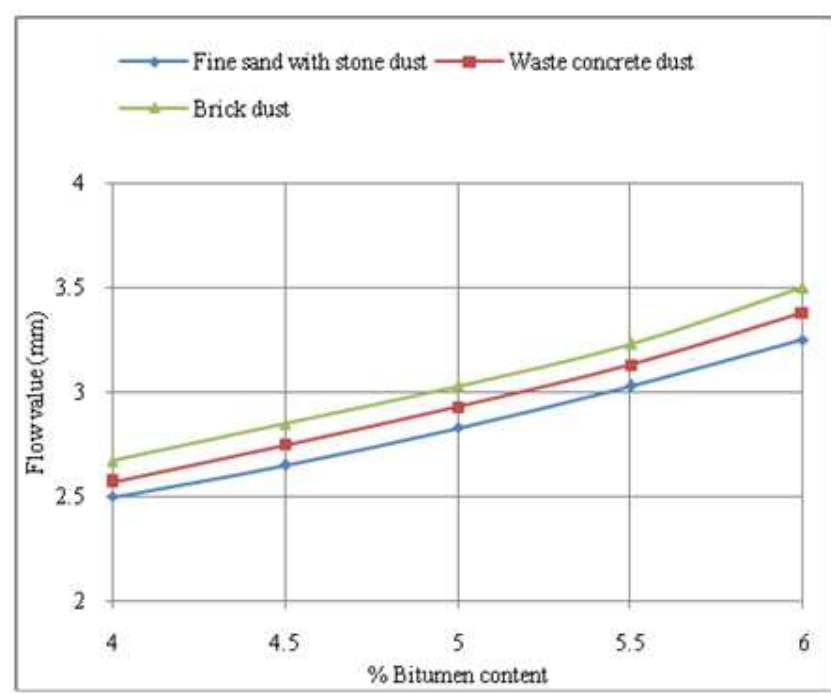

Figure 9. Variation of flow value with bitumen content (\%).

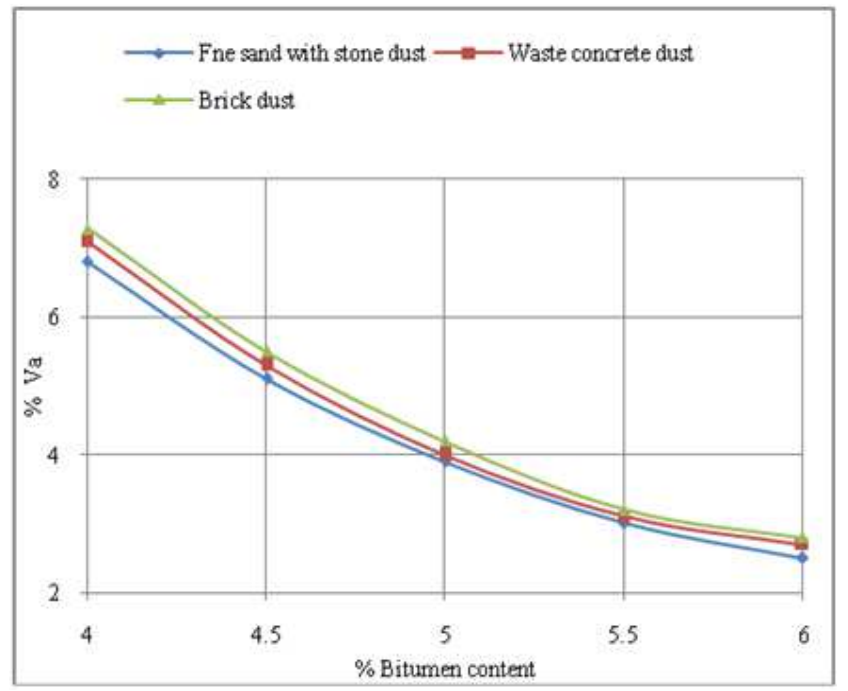

Figure 10. Variation of $\% V_{a}$ with bitumen content (\%).

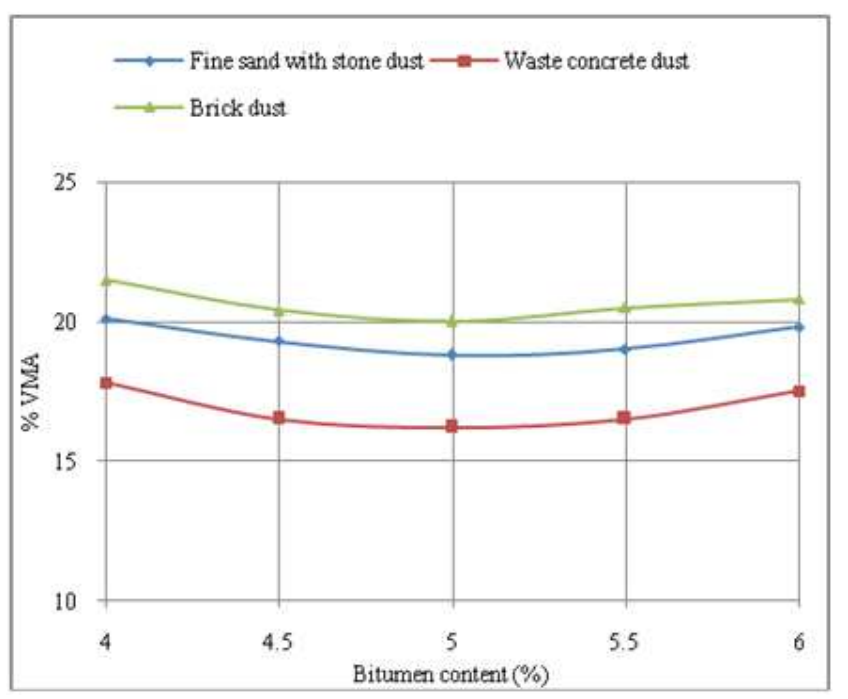

Figure 11. Variation of $\%$ VMA with bitumen content (\%).

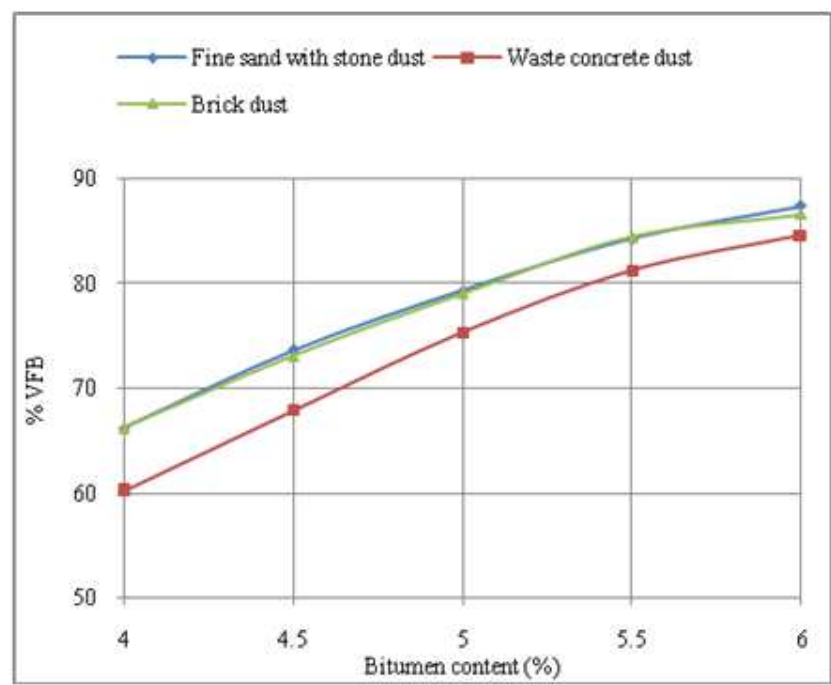

Figure 12. Variation of $\%$ VFB with bitumen content (\%).

Figure 8 showing the relationship between Marshall Stability and bitumen content which is similar in nature to that of unit weight. At optimum bitumen content bituminous mixes containing brick dust and waste concrete dust as filler displayed stability of $11.18 \mathrm{KN}$ and $11 \mathrm{KN}$ respectively which are higher than the value $9.68 \mathrm{KN}$ obtained for mix containing fine sand with stone dust as filler. Marshall Stability increases with the increase of viscosity of the asphalt cement. So the addition of brick dust and waste concrete dust filler in the mixture may produce a more viscous asphalt cement mixture binder thus increasing the stability.

Figure 9 showing the relationship between flow value and bitumen content, which indicates that the flow value of the specimens increase with increase in bitumen content. The rate of increase is being higher for higher proportions of bitumen. The value obtained for mixes with brick dust and waste concrete dust as filler are higher than the mix containing fine sand with stone dust as filler which indicates that brick dust and waste concrete dust are coarser than fine sand with stone dust mix. This means the more fine filler (e.g. fine sand with 
stone dust) tempers the bitumen mixtures by extending the bitumen binder, hence gives lower stability.

Figure 10 showing the relationship between percent air voids in total mix and bitumen content. It indicates higher percentages of voids in mineral aggregate were obtained from mixes prepared by brick dust filler. This may be due to the fact that brick dust filler is coarser than waste concrete dust and fine sand with stone dust filler.

Figure 11 showing the relationship between percent voids in mineral aggregate and bitumen content, which shows that the percentage of voids in mineral aggregates decreases initially with an increase in bitumen content, reaches a minimum value and then increases. It indicates higher percentages of voids in mineral aggregate were obtained from mixes prepared by brick dust filler. This is because brick dust filler is coarser than fine sand with stone dust filler. A minimum percentage of VMA is required in mixtures to allow adequate bitumen content to coat aggregate particles with sufficient bitumen
Figure 12 showing the relationship between percent voids filled with bitumen and bitumen content. It indicates that the $\% \mathrm{VFB}$ of compacted specimens for the mixes increases with an increase in bitumen content.

The test results obtain for the three types of filler specimens satisfies the standard value specified by Roads \& Highways Department of Bangladesh, only the exception is that the \%VMA obtains for brick dust filler specimen is slightly more than the standard value. Also the value of $\%$ VFB calculated for three types of filler exceed the standard limit.

At optimum bitumen content, the values of unit weight, Marshall Stability, flow value, percent air voids $\left(\% \mathrm{~V}_{\mathrm{a}}\right)$, percent voids in mineral aggregate (\%VMA) and percent voids filled with bitumen (\%VFB) are shown in table 7 . It indicate that bituminous mixes with non-conventional filler (e.g. waste concrete dust \& brick dust) are found to have satisfactory Marshall properties, which are almost same as those of conventional fillers (e.g. .fine sand stone dust mix) .

Table 7. Comparison between three types of mineral filler.

\begin{tabular}{|c|c|c|c|c|}
\hline Properties & Fine sand and stone dust mix & Waste concrete dust & Brick dust & Standard values (RHD,Bangladesh) \\
\hline OBC & 5.3 & 5.33 & 5.37 & $4.9-6.5$ \\
\hline Unit weight $\left(\mathrm{kg} / \mathrm{m}^{3}\right)$ & 2393.4 & 2396.98 & 2388 & - \\
\hline Stability $(\mathrm{kN})$ & 9.68 & 11 & 11.18 & Min. $5.33 \mathrm{kN}$ \\
\hline Flow value(mm) & 2.95 & 3.06 & 3.15 & $2-4$ \\
\hline$\% \mathrm{~V}_{\mathrm{a}}$ & 3.36 & 3.41 & 3.6 & $3-5$ \\
\hline$\%$ VMA & 18.92 & 16.40 & 20.30 & $15-20$ \\
\hline$\% \mathrm{VFB}$ & 82.23 & 79.20 & 82.23 & $70-80$ \\
\hline
\end{tabular}

Key: $\mathrm{OBC}=$ Optimum bitumen content. RHD $=$ Roads \& Highway Department.

\section{Conclusion}

(1) It is found that bituminous mixes containing waste concrete dust and brick dust as fillers have almost same Marshall Properties as those of conventional (fine sand with stone dust) fillers.

(2) It is observed that with the increase of bitumen content, the Marshall Stability of the mixture also increased. Bituminous mixes containing brick dust as filler showed maximum stability of $11.3 \mathrm{KN}$ at $5.5 \%$ bitumen content. The maximum stability value obtained for the mixes containing waste concrete dust and fine sand with stone dust as filler were $11.1 \mathrm{KN}$ and $9.8 \mathrm{KN}$ respectively.

(3) From the considerations of economy and availability, waste concrete dust and brick dust are suitable as filler as compared with mineral filler generally used in bituminous mix.

(4) With some modification in design mixes, can result in utilization of waste concrete dust and brick dust as fillers in bituminous pavement, thus save considerable investment in construction and partially solving the disposal of wastes.

\section{Acknowledgments}

For successful completion of the project authors tenders their best regard to Md. Abdul Alim, Professor and Head of the Department of Civil Engineering of Rajshahi university of Engineering \& Technology (RUET). Also thanks are credited in favors of all the laboratory assistant of the Transportation Engineering of Rajshahi university of Engineering \& Technology (RUET).

\section{References}

[1] Kadeyali: Principles and practice of Highway Engineering. $3^{\text {rd }}$ edition (1997).

[2] Katamine NM: Phosphate waste in mixtures to improve their deformation. J Transport Eng 2000; 126:382-9.

[3] Asi Ibrahim, Assa'ad Abdullah: Effect of Jordanian oil shale fly ash on asphalt mixes. J Mater CivEng 2005; 17:553-9.

[4] Lin Deng-Fong, Lin Jyh-Dong, Chen Shun-Hsing: The application of baghouse fines in Taiwan. Resour Conserv Recycle 2006; 46:281-301.

[5] Sung Do Hwang, Hee Mun Park, Suk keun Rhee: A study on engineering characteristics of asphalt concrete using filler with recycled waste lime. Waste Manage 2008; 28:191-9.

[6] Xue Yongjie, Hou Haobo, Zhu Shujing, Zha Jin: Utilization of municipal solid waste incineration ash in stone mastic asphalt mixture: pavement performance and environmental impact. Constr Build Mater 2009; 23:989-96. 
[7] Huang Baoshan, Dong Qiao, Burdette Edwin G: Laboratory evaluation of incorporating waste ceramic materials into Portland cement and asphaltic concrete. Constr Build Mater 2009; 23:3451-6.

[8] Kalkattawi, H.R: Effect of Filler on the Engineering Properties of Asphalt Mixes, M.S. Thesis, King Abdul Aziz University, Jeddah, Saudi Arabia. (1993)

[9] Anderson, D. A.: Guidelines for use of dust in hot mix asphalt concrete mixtures."Proc. Association of Asphalt Paving Technologists, 56, Association of Asphalt Paving Technologists, St. Paul, MN, 492-516, 1987

[10] Elliot, R.P., Ford, M.C., Ghanim, M., and Tu, Y.F. :Effect of aggregate gradation variation on asphalt concrete mix properties, Transportation Research Record, 1317, National Research Council, Washington, D.C., 1991

[11] Kandhal, P.S., Lynn, C.Y., and Parker, F.: Characterization tests for mineral fillers related to performance of asphalt paving mixtures, NCAT Rep. No. 98-2, 1998

[12] Bahia, H.U., Zhai, H., Bonnetti, K., and Kose, S.: Non-linear visco-elastic and fatigue properties of asphalt binders, Journal of Association of Asphalt Paving Technology, 68, 1-34,1999

[13] Geber, R. and Gomze, L.A.: Characterization of mineral materials as asphalt fillers, Material Science Forum,659, 471-476, 2010
[14] Vavrik, W.R., Pine, W.J., Carpenter, S.H., and Bailey, R.: Bailey method for gradation selection in hot-mix asphaltmixturedesign,TransportationResearchBoard,NationalR esearchCouncil,Washington,D.C., USA., 2002

[15] Zulkati, A., Diew, W. Y. and Delai, D.S. :Effects of Fillers on properties of Asphalt-Concrete Mixture, Journal of Transportation Engineering, ASCE, Vol. 138, No. 7, 902-910.,2012

[16] Taylor, R.: Surface interactions between bitumen and mineral fillers and their effects on the rheology of bitumen-filler mastics. Ph.D. thesis, Univ. of Nottingham, UK., 2007

[17] Lesueur, D.: The colloidal structure of bitumen: consequences on the rheology and on the mechanisms of bitumen modification. Adv.Colloid Interface Sci., 145(1-2), 42-82., 2009

[18] Bahia, H. U., Faheem, A., Hintz, C., Al-Qadi, I., Reinke, G., and Dukatz, E.: Test methods and specification criteria for mineral filler used in HMA."NCHRP Research Results Digest, 357, Transportation Research Board, Washington, DC., 2011

[19] American Society for Testing and Materials (ASTM): Road and Paving Materials; Vehicle Pavement System, Annual Book of ASTM Standards, Section 4, Volume 04.03,2003. 